\title{
A Plant-Feeding Nematode Indirectly Increases the Fitness of an Aphid
}

\author{
Grace A. Hoysted ${ }^{1}$, Catherine J. Lilley', Katie J. Field', Michael Dickinson², \\ Sue E. Hartley ${ }^{3}$ and Peter E. Urwin ${ }^{1 *}$ \\ ${ }^{1}$ Centre for Plant Sciences, University of Leeds, Leeds, United Kingdom, ${ }^{2}$ FERA Science Ltd., York, United Kingdom, \\ ${ }^{3}$ Department of Biology, University of York, York, United Kingdom
}

OPEN ACCESS

Edited by:

Laurent Gentzbittel,

National Polytechnic Institute

of Toulouse, France

Reviewed by:

George Newcombe,

University of Idaho, United States

Juan Emilio Palomares-Rius,

Consejo Superior de Investigaciones

Cientificas (CSIC), Spain

*Correspondence:

Peter E. Urwin

p.e.urwin@leeds.ac.uk

Specialty section This article was submitted to Plant Breeding,

a section of the journal

Frontiers in Plant Science

Received: 21 August 2017

Accepted: 19 October 2017

Published: 03 November 2017

Citation:

Hoysted GA, Lilley CJ, Field KJ,

Dickinson M, Hartley SE and

Urwin PE (2017) A Plant-Feeding Nematode Indirectly Increases

the Fitness of an Aphid.

Front. Plant Sci. 8:1897.

doi: 10.3389/fpls.2017.01897
Plants suffer multiple, simultaneous assaults from above and below ground. In the laboratory, pests and/or pathogen attack are commonly studied on an individual basis. The molecular response of the plant to attack from multiple organisms and the interaction of different defense pathways is unclear. The inducible systemic responses of the potato (Solanum tuberosum L.) host plant were analyzed to characterize the plant-mediated indirect interactions between a sedentary, endoparasitic nematode (Globodera pallida), and a phloem-sucking herbivore (Myzus persicae). The reproductive success of $M$. persicae was greater on potato plants pre-infected with $G$. pallida compared to control plants. Salicylic acid (SA) increased systemically in the leaves of potato plants following nematode and aphid infection singly with a corresponding increase in expression of SA-mediated marker genes. An increase in jasmonic acid associated with aphid infection was suppressed when plants were co-infected with nematodes. Our data suggests a positive, asymmetric interaction between a sedentary endoparasitic nematode and a sap-sucking insect. The systemic response of the potato plant following infection with $G$. pallida indirectly influences the performance of M. persicae. This work reveals additional secondary benefits of controlling individual crop pests.

\footnotetext{
Keywords: aboveground-belowground interactions, aphids, induced defenses, jasmonic acid, plant parasitic nematodes, salicylic acid
}

\section{INTRODUCTION}

Plants are simultaneously attacked by a number of invading organisms, both above and below ground. Pests and pathogens sharing the same host can, despite their spatial separation, together elicit a response that is more complex than the additive response of those sole agents (van Dam and Heil, 2011). Infection of a host plant that carries a pre-existing pest or pathogen burden will influence the success of the secondary or primary infection, depending on a range of factors including the species under investigation, the sequence of pest arrival, the severity of the infestation (Erb et al., 2011; Johnson et al., 2012; Huang et al., 2016; Papadopoulou and van Dam, 2017), and the changes in primary and secondary metabolites in the shared plant tissues (Bezemer et al., 2003; Wardle et al., 2004; Schoonhoven et al., 2005; van Geem et al., 2016). Given this context dependency, it is unsurprising that both positive and negative effects of below-ground organisms on those above-ground have been reported. For example, a positive indirect influence by generalist root herbivores resulted in an increased abundance of a tephritid (Diptera: Tephritidae) seed predator and two of its dominant parasitoids (Hymenoptera: Chalcidoidea) on the marsh thistle 
(Masters et al., 2001), whereas negative indirect effects of wireworms below ground led to a reduced performance and fecundity of the beet armyworm, a major foliage feeding pest of cotton (Bezemer et al., 2003).

Host-mediated interactions between plant-feeding organisms are particularly significant in agricultural systems: many economically important crops are attacked simultaneously by aboveground insect pests, such as aphids, and by belowground pathogens, such as plant parasitic nematodes. Aphids, the largest group of phloem feeders, use their stylet-like mouthparts to feed on photoassimilates found in the phloem sieve elements (Pollard, 1973). Aphids also transmit viruses, which can adversely affect the fitness of the host plant (Dixon and Kindlmann, 1998). Primarily, their importance is as vectors of virus diseases but due to their ability to reproduce rapidly (Foster et al., 2000), high populations can also result in substantial reductions in yield (Kolbe, 1970). Cyst nematodes are a group of highly evolved sedentary endoparasites and are pathogens of temperate, subtropical and tropical plant species. Following root penetration, cyst nematode second-stage juveniles migrate intracellularly toward the vascular cylinder where each chooses an initial syncytial cell from which it will form a highly metabolically active feeding site (Lilley et al., 2005). Large scale gene expression profiling has identified genes that are differentially regulated by cyst nematode infection following a compatible interaction (Alkharouf et al., 2006; Ithal et al., 2007; Szakasits et al., 2009) and many genes related to metabolic pathways including phytohormone regulation are up-regulated in the host plant (Uehara et al., 2010). Salicylic acid (SA)-dependent signaling seems to be crucial for resistance against biotrophic pathogens (Glazebrook, 2005; Loake and Grant, 2007) and cyst nematodes have been reported to activate a strong SA-mediated defense response in shoots of Arabidopsis thaliana from 5 days post inoculation (Wubben et al., 2008).

Although cyst nematodes and aphids may share the same host, their infection of the plant is temporally as well as spatially separated: nematodes infect plants soon after roots emerge, while aphids colonize plants later in the year, once there is sufficient biomass above ground (Van Emden et al., 1969). This temporal separation may give rise to asymmetric interactions, whereby nematodes influence the performance of aphids, but aphids do not impact on nematodes. There is some evidence to support this in that there are more studies demonstrating that nematodes have an effect on the performance and fecundity of aphids than vice versa (Kutyniok and Müller, 2012). The mechanism underpinning this asymmetric interaction may be changes to plant biomass, although changes in primary and secondary metabolites appear to be more important at least in some cases. For example, a mixed nematode infection of Pratylenchus, Meloidogyne, and Heterodera spp. has been reported to reduce the fecundity of Schizaphis rufula without significantly affecting plant biomass (Vandegehuchte et al., 2010). Similarly, an increase in phenolic content in foliar parts of plants has been reported following infection with plant parasitic nematodes (van Dam et al., 2005; Kaplan et al., 2008), which had a negative effect on the survival rate of above-ground herbivores. In a study of interactions between the soybean aphid and the soybean cyst nematode, alate aphids preferred plants without nematodes over nematodeinfested plants, though the performance and population growth of aphids feeding on nematode-infested plants was either unaffected or even slightly improved (Hong et al., 2010). Systemic changes to primary and secondary metabolites have been reported in Arabidopsis thaliana infected with the beetcyst nematode Heterodera schachtii (Hofmann et al., 2010). A similar response to $H$. schachtii in Brassica oleracea was subsequently reported to cause reduced aphid population growth and disturbed feeding relations between plants and aphids ( $\mathrm{Hol}$ et al., 2013).

Phytohormones such as SA, jasmonic acid (JA), and ethylene (ET) are, or are at least partly, shared by both abiotic and biotic stress signaling, indicating the likelihood of crosstalk and convergence of mechanisms in these molecular pathways. Research aimed at developing stress-tolerant crops is therefore increasingly focussing on crosstalk between phytohormones (Miller et al., 2010; Denancé et al., 2013; Kissoudis et al., 2014). Crosstalk between different molecular signals is a way in which plants can fine-tune their responses to stress by controlling gene expression (Pieterse et al., 2012; Lazebnik et al., 2014). Phytohormones can act either at their site of synthesis or systemically elsewhere in the plant (Peleg and Blumwald, 2011), thus attack from a pathogen at one position in a plant may indirectly affect a secondary arriving pest through plant-mediated interactions. Complex interactions between SA, JA, and ET, however, are influenced by the invading pest or pathogen and the timing of the infection (Dicke et al., 2009; Ton et al., 2009; Atkinson et al., 2015).

In this study, we examined plant-mediated interactions between the plant parasitic nematode, Globodera pallida and the generalist aphid Myzus persicae Sulzer (Hemiptera: Aphididae) in the potato crop (Solanum tuberosum cv. Désirée). The potato cyst nematode G. pallida is an important pathogen of potato crops that can cause reported yield losses in excess of 50\% (Trudgill, 1986) and the species is estimated to be present in $64 \%$ of potato-growing fields in England and Wales (Minnis et al., 2002). M. persicae feeds on a large variety of plants belonging to different families and worldwide is the most important insect pest of potato (Radcliffe, 1982). Although there is an increasing number of studies on nematode-aphid interactions in the model species Arabidopsis thaliana (Kutyniok and Müller, 2012; Kutyniok et al., 2014), the plant-mediated mechanisms responsible for such effects at both the biochemical and molecular level remain unexplored in crop plants. Using a combination of molecular and biochemical techniques, we test the hypothesis that systemic changes in endogenous phytohormones and the expression of associated genes can indirectly influence these plant-mediated interactions between organisms feeding above and below ground. We examine the induced systemic defense response of potato plants following nematode infection and how these responses impact on aphidinduced SA production which is required for systemic acquired resistance ( $\mathrm{SAR}$ ), leading to the expression of $P R$-genes. We also describe levels of endogenous JA and the expression of a gene involved in jasmonate signaling. Finally, we show the 
impact of G. pallida pre-infection of potato plants on M. persicae abundance.

\section{MATERIALS AND METHODS}

\section{Aphids and Nematodes}

Nymphs of the peach-potato aphid (Myzus persicae) were obtained from the James Hutton Institute, Invergowrie, Dundee, Scotland. The aphids were asexual clones of a wild population isolated in Scotland (Kasprowicz et al., 2008). Aphid colonies were maintained on potato plants (S. tuberosum L. cv. Désirée) inside a mesh cage in a containment glasshouse at $20-22^{\circ} \mathrm{C}$ under a $16 \mathrm{~h} / 8 \mathrm{~h}$ light/dark cycle. Only apterous (wingless) aphids were used and transferred to experimental plants using a fine paintbrush.

Cysts of G. pallida were extracted from infected soil stocks using the Fenwick can method (Fenwick, 1940). Infective secondstage juveniles (J2s) were hatched from the cysts following treatment with $1 \%$ sodium hypochlorite aqueous solution (Heungens et al., 1996). J2 nematodes were stored in autoclaved tap water at $10^{\circ} \mathrm{C}$ and their viability was checked prior to use by observation using a stereo binocular microscope.

\section{Pest and Pathogen Infection and Sample Collection}

Potato tuber cuttings (S. tuberosum L. cv. Désirée) were planted in $18 \mathrm{~cm}$ pots containing pesticide-free compost. Growth took place in a glasshouse at $20-22^{\circ} \mathrm{C}$ under a $16 \mathrm{~h} / 8 \mathrm{~h}$ light/dark cycle for a period of 3 weeks. For potato plants infected with nematodes only, 10,000 J2 nematodes suspended in $6 \mathrm{~mL}$ of autoclaved tap water were introduced into the compost around the roots of each potato plant. Uninfected potato plants used as a control were mock-inoculated with autoclaved tap water. At 14 days post inoculation (dpi), a fully expanded terminal leaf from the top of each plant was excised using fine tweezers, divided into three samples for RNA, SA, and JA extractions and immediately snap frozen in liquid nitrogen. Five-week-old potato plants were used for infection with aphids alone so ensuring each set of experimental plants were the same age. Twenty apterous aphids of various life-stages were transferred to the second fully expanded leaf with a fine paintbrush and confined to the abaxial surface of the leaf in a $2.5 \mathrm{~cm}$ diameter clip-cage. Aphid-free clip-cages were used in control experiments. After $48 \mathrm{~h}$, aphids were carefully removed and the leaf was excised and sampled as previously described. Co-infected potato plants were initially inoculated with ten thousand $\mathrm{J} 2$ nematodes, then 14 days later 20 apterous aphids were applied to either infected or control plants for $48 \mathrm{~h}$ as previously described. Co-infected samples were collected $48 \mathrm{~h}$ post infection (hpi) with aphids.

\section{RNA Extraction, cDNA Synthesis, and qRT-PCR for the Analysis of PR-Gene Expression}

Total RNA was prepared from frozen leaf tissue of control and infected potato plants using the RNeasy ${ }^{\circledR}$ Plant Mini Kit
(Qiagen, Inc., Valencia, CA, United States). First-strand cDNA was synthesized from 1000 ng RNA using SuperScript II reverse transcriptase (Invitrogen, Carlsbad, CA, United States) and oligo $(\mathrm{dT})_{17}$ primer $(500 \mu \mathrm{g} / \mathrm{ml})$ following the manufacturer's instructions. Quantitative reverse transcriptase (qRT)-PCR was carried out on the resulting cDNA using Brilliant III UltraFast SYBR $^{\circledR}$ Green Master Mix and a Mx3005P (v. 4.10) instrument (Agilent Technologies, La Jolla, CA, United States). Genes for expression analysis were selected according to their previously recorded involvement in biotic stress responses (Kombrink et al., 1988; Matton and Brisson, 1989; Fidantsef et al., 1999; Reiss and Horstmann, 2001; Wang et al., 2005) (see Results section for further details). Potato ELONGATION FACTOR 1- $\alpha$ was used to normalize the results (Nicot et al., 2005). Sequences of primers used for amplification of each gene are detailed in Supplementary Data Table 1. Sequences for the chosen genes were found on the National Center for Biotechnology Information website ${ }^{1}$ and primers were designed using the online Primer 3 software ${ }^{2}$. Controls for qRT-PCR included reactions containing no template. All primer pairs had an amplification efficiency of $93-101 \%$ and $R^{2}$ correlation coefficients for standard curves ranged between 0.94 and 0.99 . qRT-PCR was performed on five biological replicates for control and infected samples and each reaction was carried out in triplicate. $\mathrm{Ct}$ values were determined using the MxPro software. Relative expression between control and infected samples was determined using the $2^{-\Delta \Delta C_{t}}$ method (Livak and Schmittgen, 2001).

\section{Extraction and Quantification of Salicylic Acid}

Salicylic acid extraction was performed on leaf tissue that had been treated with aphids and nematodes both singly and in combination using a modified protocol derived from Raskin et al. (1989). One milliliter of methanol (90\%) was added to ground, frozen leaf tissue, and the resulting mixture was vortexed for $1 \mathrm{~min}$ followed by sonication in a bath for $5 \mathrm{~min}$. After centrifugation for $5 \mathrm{~min}$ at $14,104 \times \mathrm{g}$, the supernatant was collected and the pellet was re-extracted with $500 \mu \mathrm{l}$ methanol (100\%), vortexed for $1 \mathrm{~min}$, re-sonicated for $5 \mathrm{~min}$, and re-centrifuged at $14,104 \times g$ for a further $5 \mathrm{~min}$. Both supernatants were combined and dried using a GeneVac (EZ-2 series). For free SA quantification the dried samples were re-suspended in $250 \mu \mathrm{l}$ of $5 \%$ trichloroacetic acid (TCA) and vortexed. The sample was extracted twice in cyclohexane and ethyl acetate (1:1), vortexed vigorously and centrifuged at $14,104 \times g$ for $1 \mathrm{~min}$. The top organic phase was removed and dried using a GeneVac (EZ-2 series). The remaining phase was subjected to acid hydrolysis using $8 \mathrm{M} \mathrm{HCl}$ and incubated at $80^{\circ} \mathrm{C}$ for $1 \mathrm{~h}$ to quantify sugar-conjugated (or stored) SA. The sugar-conjugated (or stored) SA sample was extracted twice in cyclohexane and ethyl acetate (1:1), vortexed vigorously and centrifuged at $14,104 \times g$ for $1 \mathrm{~min}$. The top organic phase was removed and dried using a GeneVac.

\footnotetext{
${ }^{1}$ www.ncbi.nlm.nih.gov

${ }^{2}$ http://primer3.ut.ee/
} 
The pooled stored SA extract was re-suspended in $600 \mu \mathrm{l}$ of water and acetonitrile (95:5) and quantified by high-pressure liquid chromatography (HPLC). Analysis was performed using a Supelcosil $^{\mathrm{TM}}$ LC-18 column $(250 \mathrm{~mm} \times 4.6 \mathrm{~mm}, 5 \mu \mathrm{m})$. An injection volume of $20 \mu \mathrm{l}$ was separated under isocratic conditions using a mobile phase of water, acetonitrile (HPLC grade) and formic acid (60:40:0.1) at a flow rate of $1 \mathrm{ml} / \mathrm{min}$. SA was detected using a Dionex RF 2000 Fluorescence Detector operated at an emission wavelength of $400 \mathrm{~nm}$ and an excitation wavelength of $303 \mathrm{~nm}$, respectively. SA was determined and quantified by comparing peaks of recovered SA using calibration standards. Total SA was calculated as the amount of free SA in plant samples plus the amount of sugar-conjugated (or stored) SA in plant samples. The efficiency of SA recovery was calculated by using a deuterium-labeled internal standard of SA$\mathrm{d}_{6}$. Twelve biological replicates were used for each condition analyzed.

\section{Jasmonic Acid Quantification}

Leaf tissue was harvested as previously described. The samples were ground into a powder in a Tissue Lyser LT (Qiagen, Hilden, Germany) and $1 \mathrm{ml}$ extraction solvent (methanol $/ \mathrm{H}_{2} \mathrm{O} /$ formic acid; 80:19:1, v/v/v) was added and mixed. Samples were sonicated at $4^{\circ} \mathrm{C}$ for $5 \mathrm{~min}$, agitated for $30 \mathrm{~min}$ at $4^{\circ} \mathrm{C}$ and centrifuged at $12,000 \times g$ for $10 \mathrm{~min}$ at $4^{\circ} \mathrm{C}$. The extraction procedure was repeated with $500 \mu \mathrm{l}$ solvent and the supernatants were combined. JA was analyzed on a UPLC AxION 2 TOF MS system coupled with an Altus SQ Detector (Perkin Elmer, United Kingdom). For the chromatographic separation the solvents were $0.1 \% \mathrm{HCO}_{2} \mathrm{H}$ in ultrapure water (A) and $0.1 \%$ $\mathrm{HCO}_{2} \mathrm{H}$ in methanol (B), the column was a C18 $100 \mathrm{X} 1.2 \mathrm{~mm}$ (Perkin Elmer, United Kingdom) and the flow rate was set at $0.35 \mathrm{ml} \mathrm{min}-1$. The binary analytical gradient used was as follows: $0 \mathrm{~min}, 1 \% \mathrm{~B} ; 20 \mathrm{~min}, 100 \% \mathrm{~B} ; 22 \mathrm{~min}, 100 \% \mathrm{~B}$; $25 \mathrm{~min}, 1 \% \mathrm{~B}$. The compound quantification was assured by calibration curve standards in the range of $5-50 \mathrm{ng} / \mathrm{ml}$. The data analysis was performed using Empower 3 software (Waters, United Kingdom).

\section{Aphid Abundance}

To test the effect of $G$. pallida infection on aphids, 10 apterous adults were placed in a $2.5 \mathrm{~cm}$ diameter clip cage on a fully expanded, terminal leaf second from the top of a potato plant pre-infected with $10,000 \mathrm{~J} 2$ nematodes 14 days previously or mock-inoculated with water. After $24 \mathrm{~h}$ all aphids except for five nymphs were removed. The five nymphs were allowed to develop and the number of aphids inside the clip-cage were counted for 8 days to determine the abundance of aphids on nematodeinfested plants and non-infected control plants. Five biological replicates for each condition were used in the experiment.

\section{Data Analysis}

The effects of the treatments on gene expression and the levels of endogenous phytohormones JA and SA were determined using a Mann-Whitney $U$ test. A Mann-Whitney $U$ test was also carried out to compare the abundance of aphids on nematode infected plants against non-infected control plants.

\section{RESULTS}

\section{Infection of Potato Plants with Globodera pallida or Myzus persicae Elicits a SA-Mediated Systemic Defense Pathway in the Leaves}

There was a significant increase in endogenous SA in the leaves of potato plants 14 days after infection with G. pallida. The level of free SA was significantly greater in nematode-infected plants compared to non-infected control plants (mean \pm standard error), $571.33 \pm 70.09 \mathrm{ng} / \mathrm{g} \mathrm{FW}$ for infected plants and $231.20 \pm 27.21 \mathrm{ng} / \mathrm{g}$ FW for control plants (Mann-Whitney $U=497.5, P=0.001$, sig $\leq 0.05,2$-tailed) (Figure 1A). The presence of nematodes also significantly increased total levels of SA in leaves of potato plants, (4541.42 $\pm 268.2 \mathrm{ng} / \mathrm{g}$ FW for nematode-infected plants and $2132.77 \pm 758.57 \mathrm{ng} / \mathrm{g} \mathrm{FW}$ for control plants, $P \leq 0.01$ ) (Figure 1A). These results suggest an activation of the SAR pathway in the leaves of potato plants, which is mediated by SA (Gaffney et al., 1993).

An elevated level of the endogenous phytohormone SA is known to lead to the expression of pathogen-related $(P R)$ genes, some of which are commonly used molecular markers of SAR (Uknes et al., 1993; Bowling et al., 1994; Cao et al., 1994). We therefore measured the expression of $P R-1, P R-2$, and $P R-5$, all of which are coordinately regulated by SA (Cao et al., 1994), in nematode-infected plants $14 \mathrm{dpi}$. Transcripts of all three $P R$ genes were detected in leaf tissue from both infected and noninfected potato plants. However, only the expression of $P R-5$ was significantly induced in nematode infected plants (MannWhitney $U=1.000, P=0.027$ ) (Figure 1C). Transcripts of $P R-5$, which encodes a thaumatin-like protein, were approximately three-fold higher in nematode-infested plants relative to control plants (Figure 1C).

Five-week-old potato plants infected with aphids were analyzed for endogenous SA and the expression of SAmediated defense genes. There was a significant increase in free $(686 \pm 76 \mathrm{ng} / \mathrm{g} \mathrm{FW}, P \leq 0.001)$, stored (7010 $\pm 547 \mathrm{ng} / \mathrm{g} \mathrm{FW}$, $P \leq 0.001)$ and total $(8046 \pm 555 \mathrm{ng} / \mathrm{g} \mathrm{FW}, P \leq 0.001) \mathrm{SA}$ in the leaves of potato plants infected with aphids compared to control plants (Free: $276 \pm 32$ ng/g FW; Stored: $3581 \pm 392$ ng/g FW; Total: $4055 \pm 396 \mathrm{ng} / \mathrm{g}$ FW) (Figure 2A). The expression of SAmediated genes $P R-1(P \leq 0.001)$ and $P R-5(P \leq 0.001)$ was also significantly elevated. There was no significant increase in $P R-2$ expression (Figure 2C).

\section{Infection with Myzus persicae But Not Globodera pallida Elicits a JA-Mediated Systemic Defense Pathway in the Leaves of Potato Plants}

In addition to SA-mediated effects, it is well established that JA has an important role in the plant defense pathway. Hence, we also measured endogenous levels of JA as well as transcript levels of $J A Z-1$, which is a nuclear-localized protein involved in jasmonate signaling in addition to $P R-3$. There was a significant increase in endogenous JA in the leaves of plants infected 


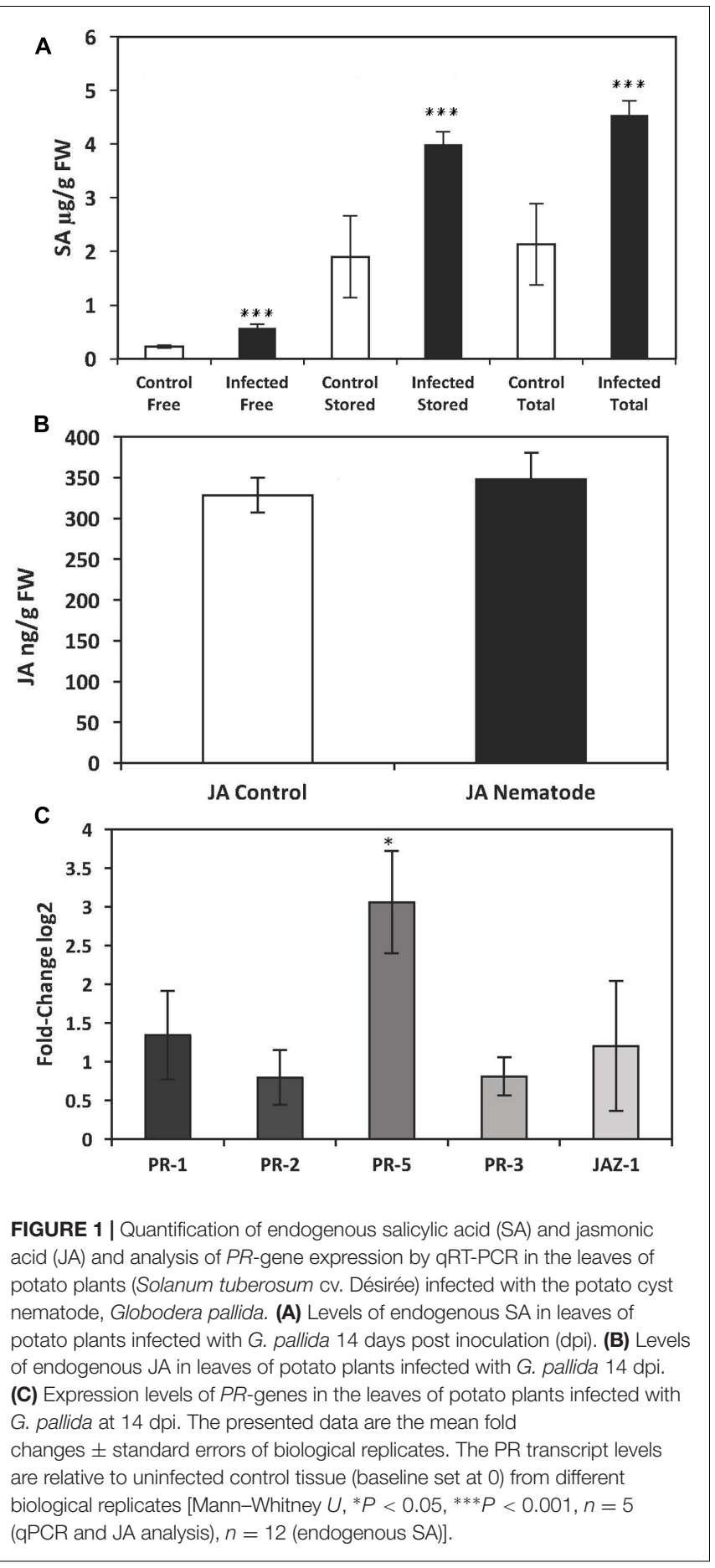

with aphids (729 $\pm 22 \mathrm{ng} / \mathrm{g}$ FW) compared to control plants (356 $\pm 88 \mathrm{ng} / \mathrm{g} \mathrm{FW})(P \leq 0.025)$ (Figure 2B). In addition there was a significant increase in transcript levels of $P R-3(P \leq 0.001)$ and $J A Z-1(P \leq 0.001)$ (Figure $2 \mathrm{C}$ ). However, there was no significant increase in endogenous levels of the phytohormone JA in nematode-infected plants $14 \mathrm{dpi}$ (Mann-Whitney $U=66.000$, $P=0.76$, sig $\leq 0.05,2$-tailed) (Figure 1B) or in the expression of genes involved in the signaling of JA, $P R-3(P \leq 0.11)$ or JAZ-1
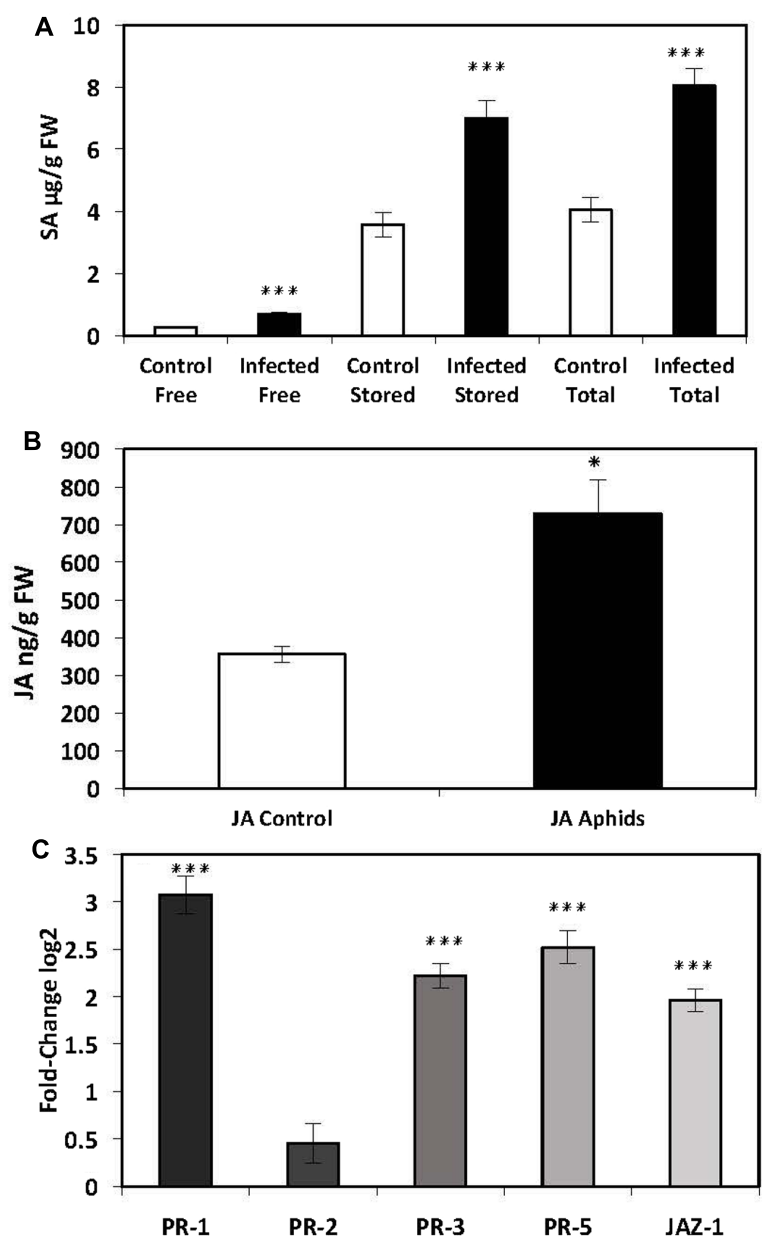

FIGURE 2 | Quantification of endogenous SA and JA and analysis of PR-gene expression by qRT-PCR in the leaves of potato plants (Solanum tuberosum cv. Désirée) infected with the peach-potato aphid, Myzus persicae. (A) Levels of endogenous SA in leaves of potato plants infected with $M$. persicae $48 \mathrm{~h}$ post inoculation (hpi). (B) Levels of endogenous JA in leaves of potato plants infected with $M$. persicae 48 hpi. (C) Expression levels of $P R$-genes in the leaves of potato plants infected with $M$. persicae $48 \mathrm{hpi}$. The presented data are the mean fold changes \pm standard errors of biological replicates. The $P R$ transcript levels are relative to uninfected control tissue (baseline set at 0) from different biological replicates [Mann-Whitney $U,{ }^{*} P<0.05$, ${ }^{* * *} P<0.001$,

$n=5$ (qPCR and JA analysis), $n=12$ (endogenous SA)].

$(P \leq 0.286)$ (Figure 1C) suggesting that nematode infection does not elicit a systemic JA defense response in the leaves of potato plants.

\section{Co-infection with Both G. pallida and M. persicae Elicits an Additive SA Defense But a Reduction in the JA Defense Signaling Pathway in the Leaves of Potato Plants}

The SA-mediated defence pathway was investigated in the leaves of potato plants that had been infected with both G. pallida and $M$. persicae. There was a significant increase in the levels 


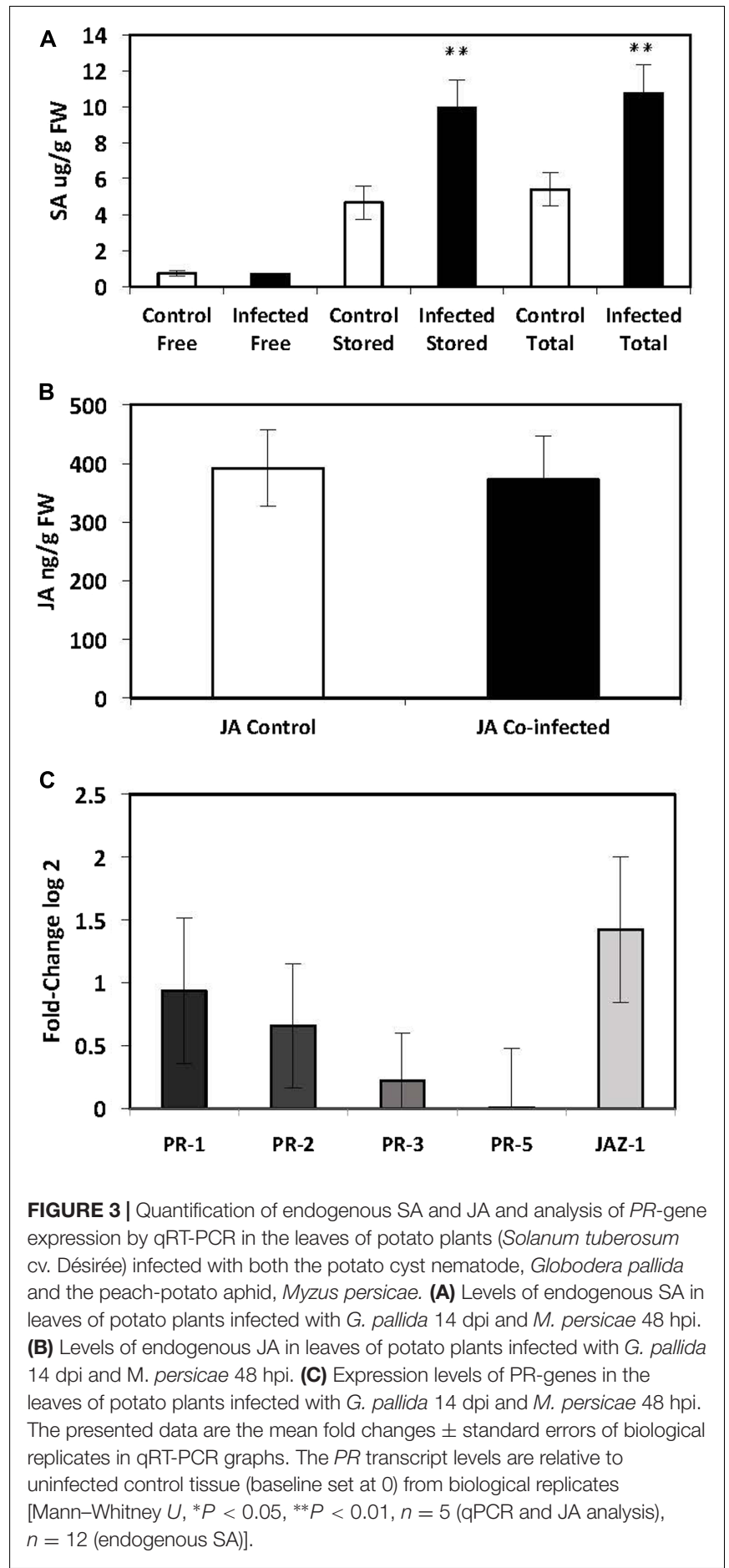

of stored (9943 $\pm 1522 \mathrm{ng})$ and total SA (10750 $\pm 1557 \mathrm{ng})$ in the leaves of dual infected plants compared to the controls (Stored: $4665 \pm 906$ ng; Total: $5409 \pm 930$ ng; $P \leq 0.012$ ) (Figure 3A). There was no significant difference in the levels of free SA in the leaves of plants that were co-infected $(691 \pm 45 \mathrm{ng})$ compared to the controls (743 $\pm 146 \mathrm{ng}$ ) (Figure 3A). There was no significant increase in transcript levels of SA-mediated defense genes (Figure 3A). The significant increase in the levels of stored SA indicates that the SA-mediated defense pathway is up-regulated in the leaves of potato plants; however, it has not been converted into free SA.

There was no significant change in the level of endogenous JA in plants that had been co-infected with both pests ( $372 \pm 73 \mathrm{ng})$ compared to the controls (392 $\pm 64, P \leq 0.855)$ (Figure 3B). Similarly, when the expression of genes involved in the JA signaling pathway were analyzed, there were no significant differences between the leaves of co-infected plants and control plants (Figure 3C). Due to a significant increase in endogenous levels of JA and the expression of SA-mediated defenses in the leaves of plants infected with aphids only, the reduction of JA in co-infected plants may indicate an antagonistic suppression of JA by the additive increase in SA caused by both nematode and aphid infection together.

\section{The Peach-Potato Aphid, Myzus persicae Has a Higher Abundance on Potato Plants Pre-infected with Globodera pallida}

There was a significant increase in the abundance of aphids reared on potato plants pre-infected with nematodes for 14 days compared with aphids reared on non-infected control plants (Mann-Whitney $U=3.000, P=0.011$, sig $\leq 0.05$, 2-tailed) (Figure 4).

\section{DISCUSSION}

Our results show how the molecular and biochemical response of the potato plant to attack by a below-ground pathogen, in this case plant-parasitic nematodes, can indirectly influence herbivore populations above ground through systemic changes in endogenous phytohormones and expression of associated genes.

\section{Plant Responses to Cyst Nematode and Aphid Infection Singly and in Combination}

Previous studies have revealed that defense signaling pathways are involved in compatible interactions of plants with cyst nematodes (Heterodera and Globodera spp.) (Jammes et al., 2005; Ithal et al., 2007; Wubben et al., 2008). Similarly, it is well known that many plant defense signaling pathways are up-regulated in response to aphid feeding (De Vos et al., 2005; Kuśnierczyk et al., 2008; Broekgaarden et al., 2011). Our analysis has shown that expression of $P R-5$, a molecular marker commonly used to indicate activation of SAR (Uknes et al., 1993; Bowling et al., 1994), was significantly increased in leaves of potato plants following infection with G. pallida for 14 days and also in the leaves of 5-week-old plants infected with M. persicae for $48 \mathrm{~h}$. This correlates with the significant increase in free and total SA in leaves of potato plants: the accumulation of the phytohormone $\mathrm{SA}$ is required for the activation of SAR in distal tissues of the infected plant (Gaffney et al., 1993). Taken together these results indicate activation of a SAR-induced potato defense pathway following parasitism by G. pallida and infection with $M$. persicae 


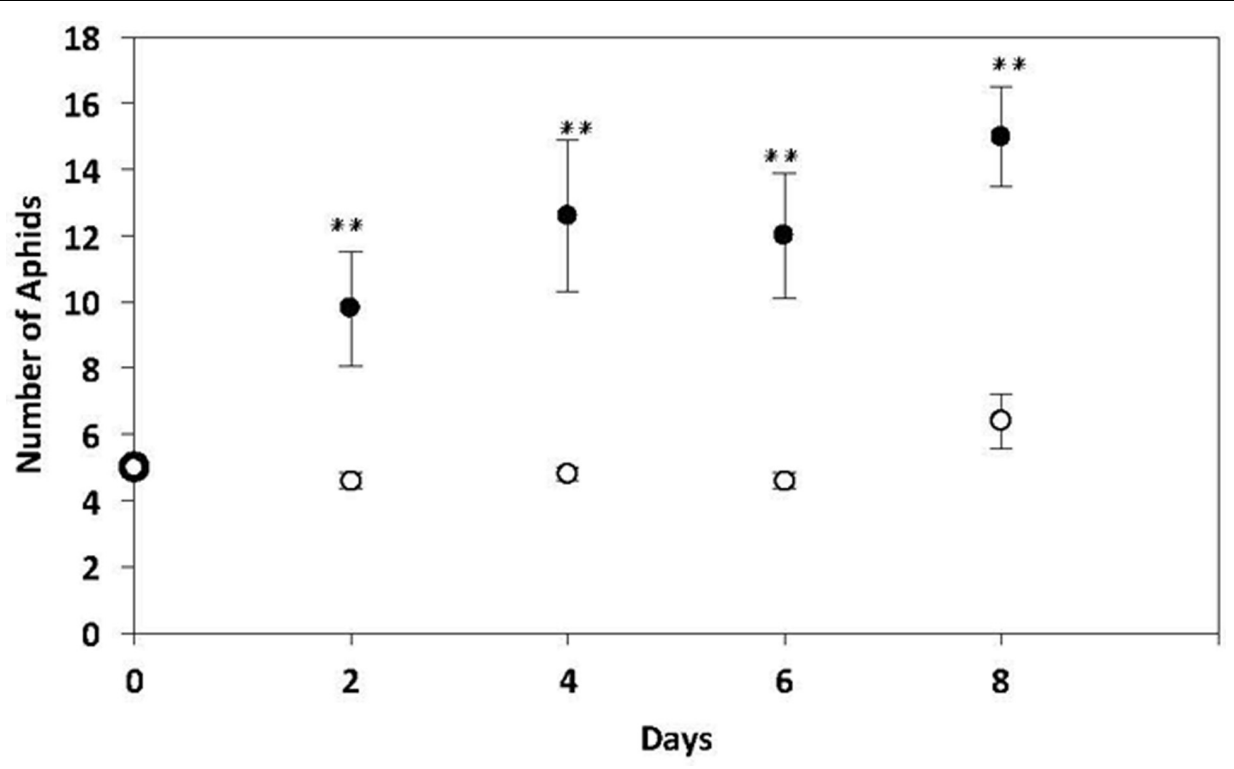

FIGURE 4 | No choice performance assays of M. persicae on potato plants pre-infected with 10,000 G. pallida J2s for 14 days or non-infected control potato plants. Black dots represent aphids present on plant pre-infected with nematodes. White dots represent aphids present on non-infected control plants. There were more M. persicae present on nematode-infested plants from day 2 to day 8 compared to non-infected control plants $(n=5$, $* * P<0.01)$.

singly. There was no significant increase in the expression $P R$ 1 or $P R-2$ in the leaves of nematode-infected potato plants at the time-point examined. Expression of the orthologous genes was reported to increase in the leaves of Arabidopsis thaliana in response to cyst nematode infection, however, this increase was transient and varied considerably between investigations (Wubben et al., 2008; Hamamouch et al., 2011). The length of time post-infection, together with the initial nematode burden, may be critical in determining if $P R$-gene induction is observed. It is well documented that there is mutual antagonism between SA and JA signaling pathways (Pieterse et al., 2012), therefore the phytohormone JA and the expression levels of the JAdependent associated genes $P R-3$ and $J A Z-1$, a nuclear-localized protein involved in jasmonate signaling (Thines et al., 2007) were quantified. No significant differences were found between nematode-infected plants and control plants in either the amount of JA or the expression of $P R-3$ and JAZ-1, suggesting that infection with the potato cyst nematode does not alter the JA signaling pathway in the potato plant at $14 \mathrm{dpi}$. Alternatively, this could indicate antagonistic cross-talk between the SA and JA pathways following infection with G. pallida, as both endogenous SA and the expression of PR-5 was significantly up-regulated. In contrast, it was found that aphid infection induced the JA signaling pathway in the leaves of potato plants as both JA and the expression of $P R-3$ and $J A Z-1$ were significantly up-regulated compared to control plants.

Co-infection of the potato with both G. pallida and M. persicae had a different and unique impact on the levels of endogenous phytohormones and expression of defense-related genes compared to plants that had been infected with each pest singly. An additive effect on SA was observed in co-infected plants, an effect that may be assumed when two pests are applied to a plant. However, a reduced JA effect was noted in dual infected plants even though JA was present in the leaves of plants infected with aphids in isolation. There is literature to suggest that phytohormones do not act independently of one another. The interaction between SA and JA is complex with the main interaction between these two pathways being mutual antagonism (Kunkel and Brooks, 2002). SA has been shown to have an inhibitory effect on JA in tomato (Doherty et al., 1988; Pena-Cortés et al., 1993) and in Arabidopsis (Clarke et al., 2000; Gupta et al., 2000). Therefore, a lack of JA in the leaves of co-infected plants could be construed as antagonistic crosstalk because although infection with plant-parasitic nematodes did not elicit the JA defense pathway in potato plants, infection with aphids alone did.

\section{Herbivore Responses to Plant Parasitic Nematode Infection}

Plant-mediated interactions between plant parasitic nematodes and aerial pests studied to date have been variable: susceptibility to shoot pathogens and resistance to phloem feeders have been reported with the outcome depending on the parasitic strategy of the nematode involved in the interaction (Biere and Goverse, 2016). To the best of our knowledge there have been no studies of plant-mediated interactions between the potato cyst nematode and specialized above-ground pests or pathogens of potato, however, there have been reports of interactions between G. rostochiensis and below-ground pathogens such as the soilborne fungus of potato, Rhizoctonia solani (Back et al., 2006). A reduced aphid performance was reported when Plantago lanceolata (Wurst and van der Putten, 2007) was infected with the migratory nematode, Pratylenchus penetrans. Similarly, a 
decrease in the fecundity of aphids was observed when Agrostis capillaris was infected with a mixture consisting of ectoparasites and migratory endoparasites (Bezemer et al., 2003). Reports using sedentary endoparasites have found negative or neutral impacts on aphids. An infection of $H$. schachtii on B. oleracea resulted in reduced growth and fecundity of a specialist aphid species, Brevicoryne brassicae as well as a generalist species, M. persicae (Hol et al., 2013). However, in another study using a mix of different parasitic nematode species, no effect on the performance of B. brassicae was found (Kabouw et al., 2011). Our observation that G. pallida, a sedentary endoparasitic nematode, indirectly and positively influences the abundance of $M$. persicae highlights how aphids may be more damaging to the potato crop in areas where G. pallida is present compared to such areas where there is no infection, however, this requires further investigation. Our study is in contrast to these previous studies and to our knowledge is the first to report the combined molecular and biochemical response of the potato to nematode infection.

Systemic plant resistance to insect herbivores is mediated by the SA and JA wound signaling pathways and the, usually antagonistic, crosstalk between them (Pieterse et al., 2012; Stam et al., 2014). In addition to their role in regulating resistance to biotrophic pathogens, SA-mediated defensive pathways are known to be induced by phloem-feeding insects, and there have also been reports suggesting that SA itself is an effective chemical defense against phloem-sucking herbivory animals (Kaloshian and Walling, 2005; Donovan et al., 2013). As expected, we found induction of the SA pathway in response to nematodes, but any adverse effects of this on the aphids are likely to be negated by the benefits of SA-mediated reductions of the JA-mediated pathway responsible for plant resistance to herbivores (Lazebnik et al., 2014). Indeed, aphids are believed to circumvent the plant's immune system by eliciting the SA signaling pathway in order to antagonize and suppress the JA one, which is important in mediating resistance to phloem feeders (Ellis et al., 2002; ZhuSalzman et al., 2004). Thus, our observation of more aphids present on nematode infested plants could reflect circumvention of the SA-mediated defense pathway of the potato plant by $M$. persicae. Our analysis of the JA-mediated defense pathway in the potato plant showed no up-regulation of endogenous JA or expression of $P R-3$ or $J A Z-1$ in leaves of potato plants infected with nematodes when compared to control plants. Aphids could

\section{REFERENCES}

Alkharouf, N. W., Klink, V. P., Chouikha, I. M., Beard, H. S., MacDonald, M., Meyer, S., et al. (2006). Timecourse microarray analyses reveal global changes in gene expression of susceptible Glycine max (soybean) roots during infection by Heterodera glycines (soybean cyst nematode). Planta 224, 838-852. doi: 10.1007/s00425-006-0270-8

Atkinson, N. J., Jain, R., and Urwin, P. E. (2015). "The response of plants to simultaneous biotic and abiotic stress," in Combined Stresses in Plants, ed. R. Mahalingam (Berlin: Springer).

Back, M., Haydock, P., and Jenkinson, P. (2006). Interactions between the potato cyst nematode Globodera rostochiensis and diseases caused by Rhizoctonia solani AG3 in potatoes under field conditions. Eur. J. Plant Pathol. 114, 215-223. doi: $10.1007 / \mathrm{s} 10658-005-5281-y$ benefit from the situation in which the hormone has not been elicited or even suppressed.

\section{CONCLUSION}

Our biochemical and molecular data reveal the potential mechanisms underpinning a positive asymmetric interaction between a sedentary endoparasitic nematode and a sap-sucking insect. The SA pathway and PR defense gene expression is altered in the potato plant following infection with G. pallida and these changes indirectly influence the performance of the peach potato aphid $M$. persicae. Our study highlights how multiple stresses elicit a unique molecular and biochemical response compared to singly stressed plants. It also demonstrates the importance of analysing hormonal crosstalk when seeking to understand plant defensive responses to co-incident attack by pests and pathogens.

\section{AUTHOR CONTRIBUTIONS}

Designed research: GH, CL, MD, SH, and PU. Performed research: GH. Analyzed the data: GH, KJF, and MD. Wrote the manuscript: GH, CL, KJF, MD, SH, and PU.

\section{ACKNOWLEDGMENTS}

The study was funded by a Biotechnology and Biological Sciences Research Council (BBSRC) Grant BB/K020706/1. We would like to thank the alumni-supported research program on sustainable agriculture and global food security for awarding funds to aid the study. We would like to thank Dr. Iain Manfield (University of Leeds) for his technical help and assistance with the HPLC studies and to Mr. Marc Parker (FERA Science Ltd.) for his assistance and support during the study.

\section{SUPPLEMENTARY MATERIAL}

The Supplementary Material for this article can be found online at: https://www.frontiersin.org/articles/10.3389/fpls.2017.01897/ full\#supplementary-material

Bezemer, T. M., Wagenaar, R., van Dam, N., and Wäckers, F. (2003). Interactions between above- and belowground insect herbivores as mediated by the plant defence system. Oikos 101, 555-562. doi: 10.1034/j.1600-0706.2003. 12424.x

Biere, A., and Goverse, A. (2016). Plant-mediated systemic interactions between pathogens, parasitic nematodes, and herbivores above- and belowground. Annu. Rev. Phytopathol. 54, 499-527. doi: 10.1146/annurev-phyto-080615100245

Bowling, S. A., Guo, A., Cao, H., Gordon, A. S., Klessig, D. F., and Dong, X. (1994). A mutation in Arabidopsis that leads to constitutive expression of systemic acquired resistance. Plant Cell 6, 1845-1857. doi: 10.1105/tpc.6.12. 1845

Broekgaarden, C., Voorrips, R. E., Dicke, M., and Vosman, B. (2011). Transcriptional responses of Brassica nigra to feeding by specialist insects of 
different feeding guilds. Insect Sci. 18, 259-272. doi: 10.1111/j.1744-7917.2010. 01368.x

Cao, H., Bowling, S. A., Gordon, A. S., and Dong, X. (1994). Characterisation of an Arabidopsis mutant that is nonresponsive to inducers of systemic acquired resistance. Plant Cell 6, 1583-1592. doi: 10.1105/tpc.6.11.1583

Clarke, J. D., Volko, S. M., Ledford, H., Ausubel, F. M., and Dong, X. (2000). Roles of salicylic acid, jasmonic acid, ethylene in cpr-induced resistance in Arabidopsis. Plant Cell 12, 2175-2190. doi: 10.1105/tpc.12.11.2175

De Vos, M., van Oosten, V. R., van Poecke, R. M., van Pelt, J. A., Pozo, M. J., Mueller, M. J., et al. (2005). Signal signature and transcriptome changes of Arabidopsis during pathogen and insect attack. Mol. Plant Microbe Interact. 18, 923-937. doi: 10.1094/MPMI-18-0923

Denancé, N., Sánchez-Vallet, A., Goffner, D., and Molina, A. (2013). Disease resistance or growth: the role of plant hormones in balancing immune responses and fitness costs. Front. Plant Sci. 4:155. doi: 10.3389/fpls.2013.00155

Dicke, M., van Loon, J. J., and Soler, R. (2009). Chemical complexity of volatiles from plants induced by multiple attack. Nat. Chem. Biol. 5, 317-324. doi: 10. 1038/nchembio. 169

Dixon, A. F. G., and Kindlmann, P. (1998). "Population dynamics of aphids," in Insect Populations in Theory and in Practice, eds J. P. Dempster and I. F. G. McLean (Dordrecht: Kluwer), 207-230. doi: 10.1007/978-94-011-4914-3_9

Doherty, H. M., Selvendran, R. R., and Bowles, D. J. (1988). The wound response of tomato plants can be inhibited by aspirin and related hydroxyl-benzoic acids. Physiol. Mol. Plant Pathol. 33, 377-384. doi: 10.1016/0885-5765(88)90004-5

Donovan, M. P., Nabity, P. D., and DeLucia, E. H. (2013). Salicylic acid-mediated reductions in yield in Nicotiana attenuata challenged by aphid herbivory. Arthropod Plant Interact. 7, 45-52. doi: 10.1007/s11829-012-9220-5

Ellis, C., Karafyllidis, I., and Turner, J. G. (2002). Constitutive activation of jasmonate signalling in an Arabidopsis mutant correlates with enhanced resistance to Erysiphe cichoracearum, Pseudomonas syringae, and Myzus persicae. Mol. Plant Microbe Interact. 15, 1025-1030. doi: 10.1094/MPMI.2002. 15.10.1025

Erb, M., Robert, C. A., Hibbard, B. E., and Turlings, T. C. (2011). Sequence of arrival determines plant-mediated interactions between herbivores. J. Ecol. 99, 7-15. doi: 10.1111/j.1365-2745.2010.01757.x

Fenwick, D. W. (1940). Methods for the recovery and counting of cysts of Heterodera schachtii from soil. J. Helminthol. 18, 155-172. doi: 10.1017/ S0022149X00031485

Fidantsef, A. L., Stout, M. J., Thaler, J., Duffey, S., and Bostock, R. (1999). Signal interactions in pathogen and insect attack: expression of lipoxygenase, proteinase inhibitor II, and pathogenesis-related protein P4 in the tomato, Lycopersicon esculentum. Physiol. Mol. Plant Pathol. 54, 97-114. doi: 10.1006/ pmpp. 1998.0192

Foster, S. P., Denholm, I., and Devonshire, A. L. (2000). The ups and downs of insecticide resistance in peach-potato aphids, Myzus persicae in the UK. Crop Protect. 19, 873-879. doi: 10.1016/S0261-2194(00)00115-0

Gaffney, T., Friedrich, L., Vernooji, B., Negrotto, D., Nye, G., Uknes, S., et al. (1993). Requirement of salicylic acid for the induction of systemic acquired resistance. Science 261, 754-754. doi: 10.1126/science.261.5122.754

Glazebrook, J. (2005). Contrasting mechanisms of defence against biotrophic and necrotrophic pathogens. Annu. Rev. Phytopathol. 43, 205-227. doi: 10.1146/ annurev.phyto.43.040204.135923

Gupta, V., Willits, M. G., and Glazebrook, J. (2000). Arabidopsis thaliana EDS4 contributes to salicylic acid (SA)-dependent expression of defence responses: evidence for inhibition of jasmonic acid signalling by SA. Mol. Plant Microbe Interact. 13, 503-511. doi: 10.1094/MPMI.2000.13.5.503

Hamamouch, N., Li, C., Seo, P. J., Park, C.-M., and Davis, E. L. (2011). Expression of Arabidopsis pathogenesis-related genes during nematode infection. Mol. Plant Pathol. 12, 355-364. doi: 10.1111/j.1364-3703.2010.00675.x

Heungens, K., Mugniéry, D., van Montagu, M., Gheysen, G., and Niebel, A. (1996). A method to obtain disinfected Globodera infective juveniles directly from cysts. Fundament. Appl. Nematol. 19, 91-93.

Hofmann, J., El Ashry, A. E. N., Anwar, S., Erban, A., Kopka, J., and Grundler, F. (2010). Metabolic profiling reveals local and systemic responses of host plants to nematode parasitism. Plant J. 62, 1058-1071. doi: 10.1111/j.1365-313X.2010. 04217.x

Hol, W. G., De Boer, W., Termorshuizen, A. J., Meyer, K. M., Schneider, J. H., van der Putten, W. H., et al. (2013). Heterodera schachtii nematodes interfere with aphid-plant relations on Brassica oleracea. J. Chem. Ecol. 39, 1193-1203. doi: 10.1007/s10886-013-0338-4

Hong, S. C., Donaldson, J., and Gratton, C. (2010). Soybean cyst nematode effects on soybean aphid preference and performance in the laboratory. Environ. Entomol. 39, 1561-1569. doi: 10.1603/EN10091

Huang, W., Robert, C. A., Hervé, M. R., Hu, L., Bont, Z., and Erb, M. (2016). A mechanism for sequence specificity in plant-mediated interactions between herbivores. New Phytol. 214, 169-179. doi: 10.1111/nph.14328

Ithal, N., Recknor, J., Nettleton, D., Hearne, L., Maier, T., Baum, T. J., et al. (2007). Parallel genome-wide expression profiling of host and pathogen during soybean cyst nematode infection of soybean. Mol. Plant Microbe Interact. 20, 293-305. doi: 10.1094/MPMI-20-3-0293

Jammes, F., Lecomte, P., Almeida-Engler, J., Bitton, F., Martin-Magniette, M. L., Renou, J. P., et al. (2005). Genome-wide expression profiling of the host response to root-knot nematode infection in Arabidopsis. Plant J. 44, 447-458. doi: 10.1111/j.1365-313X.2005.02532.x

Johnson, S. N., Clark, K. E., Hartley, S. E., Jones, T. H., McKenzie, S. W., and Koricheva, J. (2012). Aboveground-belowground herbivore interactions: a meta-analysis. Ecology 93, 2208-2215. doi: 10.1890/112272.1

Kabouw, P., Kos, M., Kleine, S., Vokenhuber, E. A., Van Loon, J. J. A., Van der Putten, W. H., et al. (2011). Effects of soil organisms on aboveground multitrophic interactions are consistent between plant genotypes mediating the interaction. Entomol. Exp. Appl. 139, 197-206. doi: 10.1111/j.1570-7458.2011. 01123.x

Kaloshian, I., and Walling, L. (2005). Hemipterans as plant pathogens. Annu. Rev. Phytopathol. 43, 491-521. doi: 10.1146/annurev.phyto.43.040204. 135944

Kaplan, I., Halitschke, R., Kessler, A., Rehill, B. J., Sardanelli, S., and Denno, R. F. (2008). Physiological integration of roots and shoots in plant defence strategies link above- and belowground herbivory. Ecol. Lett. 11, 841-851. doi: 10.1111/j. 1461-0248.2008.01200.x

Kasprowicz, L., Malloch, G., Pickup, J., and Fenton, B. (2008). Spatial and temporal dynamics of Myzus persicae clones in fields and suction traps. Agric. For. Entomol. 10, 91-100. doi: 10.1111/j.1461-9563.2008.00365.x

Kissoudis, C., van de Wiel, C., Visser, R. G., and van der Linden, G. (2014). Enhancing crop resilience to combined abiotic and biotic stress through the dissection of physiological and molecular crosstalk. Front. Plant Sci. 5:207. doi: $10.3389 /$ fpls.2014.00207

Kolbe, W. (1970). Influence of direct feeding damage on yields of heavily aphidinfested potato crops. Pflanzens. Nachr. Bayer 23, 273-282.

Kombrink, E., Schröder, M., and Hahlbrock, K. (1988). Several "pathogenesisrelated" proteins in potato are 1, 3- $\beta$-glucanases and chitinases. Proc. Natl. Acad. Sci. U.S.A. $85,782-786$. doi: 10.1073/pnas. 85.3 .782

Kunkel, B. N., and Brooks, D. M. (2002). Crosstalk between signalling pathways in pathogen defence. Curr. Opin. Plant Biol. 5, 325-331. doi: 10.1016/S13695266(02)00275-3

Kuśnierczyk, A., Winge, P., Jørstad, T. S., Troczynska, J., Rossiter, J. T., and Bones, A. M. (2008). Towards global understanding of plant defence against aphidstiming and dynamics of early Arabidopsis defence responses to cabbage aphid (Brevicoryne brassicae) attack. Plant Cell Environ. 31, 1097-1115. doi: 10.1111/ j.1365-3040.2008.01823.x

Kutyniok, M., and Müller, C. (2012). Crosstalk between above- and belowground herbivores is mediated by minute metabolic responses of the host Arabidopsis thaliana. J. Exp Bot. 63, 6199-6210. doi: 10.1093/jxb/ers274

Kutyniok, M., Persicke, M., and Müller, C. (2014). Effects of root herbivory by nematodes on the performance and preference of a leaf-infesting generalist aphid depend on nitrate fertilisation. J. Chem. Ecol. 40, 118-127. doi: 10.1007/ s10886-014-0387-3

Lazebnik, J., Frago, E., Dicke, M., and van Loon, J. J. (2014). Phytohormone mediation of interactions between herbivores and plant pathogens. J. Chem. Ecol. 40, 730-741. doi: 10.1007/s10886-014-0480-7

Lilley, C. J., Atkinson, H. J., and Urwin, P. E. (2005). Molecular aspects of cyst nematodes. Mol. Plant Pathol. 6, 577-588. doi: 10.1111/j.1364-3703.2005. 00306.x

Livak, K. J., and Schmittgen, T. D. (2001). Analysis of relative gene expression data using real-time quantitative PCR and the $2^{-\Delta \Delta C_{\mathrm{T}}}$ method. Methods 25 , 402-408. doi: 10.1006/meth.2001.1262 
Loake, G., and Grant, M. (2007). Salicylic acid in plant defence - the players and protagonists. Curr. Opin. Plant Biol. 10, 466-472. doi: 10.1016/j.pbi.2007.08.008

Masters, G. J., Hefin Jones, T., and Rogers, M. (2001). Host-plant mediated effects of root herbivory on insect seed predators and their parasitoids. Oecologia 127, 246-250. doi: 10.1007/s004420000569

Matton, D. P., and Brisson, N. (1989). Cloning, expression and sequence conservation of pathogenesis-related gene transcripts of potato. Mol. Plant Microbe Interact. 2, 325-331. doi: 10.1094/MPMI-2-325

Miller, G., Suzuki, N., Ciftci-Yilmaz, S., and Mittler, R. (2010). Reactive oxygen species homeostasis and signalling during drought and salinity stress. Plant Cell Environ. 33, 453-467. doi: 10.1111/j.1365-3040.2009.02041.x

Minnis, S., Haydock, P. P. J., Ibrahim, S., Grove, I., Evans, K., and Russell, M. (2002). Potato cyst nematodes in England and Wales - occurrence and distribution. Ann. Appl. Biol. 140, 187-195. doi: 10.1111/j.1744-7348.2002. tb00172.x

Nicot, N., Hausman, J. F., Hoffmann, L., and Evers, D. (2005). Housekeeping gene selection for real-time RT-PCR normalisation in potato during biotic and abiotic stress. J. Exp. Biol. 56, 2907-2914. doi: 10.1093/jxb/eri285

Papadopoulou, G. V., and van Dam, N. M. (2017). Mechanisms and ecological implications of plant-mediated interactions between belowground and aboveground insect herbivores. Ecol. Res. 32, 13-26. doi: 10.1007/s11284-0161410-7

Peleg, Z., and Blumwald, E. (2011). Hormone balance and abiotic stress tolerance in crop plants. Curr. Opin. Plant Biol. 14, 290-295. doi: 10.1016/j.pbi.2011. 02.001

Pena-Cortés, H., Albrecht, T., Prat, S., Weiler, E. W., and Willmitzer, L. (1993). Aspirin prevents wound-induced gene expression in tomato leaves by blocking jasmonic acid biosynthesis. Planta 191, 123-128. doi: 10.1007/BF00240903

Pieterse, C. M. J., van der Does, D., Zamioudis, C., Leon-Ryas, A., and van Wees, S. C. M. (2012). Hormonal modulation of plant immunity. Annu. Rev. Cell Dev. Biol. 28, 489-521. doi: 10.1146/annurev-cellbio-092910-154055

Pollard, D. G. (1973). Plant penetration by feeding aphids (Hemiptera, Aphidoidea): a review. Bull. Entomol. Res. 62, 631-714. doi: 10.1017/ S0007485300005526

Radcliffe, E. B. (1982). Insect pests of potato. Annu. Rev. Entomol. 27, 173-204. doi: 10.1146/annurev.en.27.010182.001133

Raskin, I., Turner, I. M., and Melander, W. R. (1989). Regulation of heat production in the inflorescences of an Arum lily by endogenous salicylic acid. Proc. Natl. Acad. Sci. U.S.A. 86, 2214-2218. doi: 10.1073/pnas.86.7.2214

Reiss, E., and Horstmann, C. (2001). Drechslera teres-infected barley (Hordeum vulgare L.) leaves accumulate eight isoforms of thaumatin-like proteins. Physiol. Mol. Plant Pathol. 58, 183-188. doi: 10.1006/pmpp.2001.0325

Schoonhoven, L. M., van Loon, J. J. A., and Dicke, M. (2005). Insect-Plant Biology. Oxford: Oxford University Press.

Stam, J. M., Kroes, A., Li, Y., Gols, R., van Loon, J. J., Poelman, E. H., et al. (2014). Plant interactions with multiple insect herbivores: from community to genes. Plant Biol. 65, 689-713. doi: 10.1146/annurev-arplant-050213-035937

Szakasits, D., Heinen, P., Wieczorek, K., Hofmann, J., Wagner, F., Kreil, D. P., et al. (2009). The transcriptome of syncytia induced by the cyst nematode Heterodera schachtii in Arabidopsis roots. Plant J. 57, 771-784. doi: 10.1111/j.1365-313X. 2008.03727.x

Thines, B., Katsir, L., Melotto, M., Niu, Y., Mandaokar, A., Liu, G., et al. (2007). JAZ repressor proteins are targets of the SCF (COI1) complex during jasmonate signalling. Nature 448, 661-665. doi: 10.1038/nature05960

Ton, J., Flors, V., and Mauch-Mani, B. (2009). The multifaceted role of ABA in disease resistance. Trends Plant Sci. 14, 310-317. doi: 10.1016/j.tplants.2009. 03.006
Trudgill, D. L. (1986). Yield losses caused by potato cyst nematodes: a review of the current position in Britain and prospects for improvements. Ann. Appl. Biol. 108, 181-198. doi: 10.1111/j.1744-7348.1986.tb01979.x

Uehara, T., Sugiyama, S., Matsuura, H., Arie, T., and Masuta, C. (2010). Resistant and susceptible responses in tomato to cyst nematode are differentially regulated by salicylic acid. Plant Cell Physiol. 51, 1524-1536. doi: 10.1093/pcp/ pcq109

Uknes, S., Dincher, S., Friedrich, L., Negrotto, D., Williams, S., ThompsonTaylor, H., et al. (1993). Regulation of pathogenesis-related protein-1a gene expression in tobacco. Plant Cell 5, 159-169. doi: 10.1105/tpc.5.2.159

van Dam, N. M., and Heil, M. (2011). Multitrophic interactions below and above ground: en route to the next level. J. Ecol. 99, 77-88. doi: 10.1111/j.1365-2745. 2010.01761.x

van Dam, N. M., Raaijmakers, C. E., and van der Putten, W. H. (2005). Root herbivory reduces growth and survival of the shoot feeding specialist Pieris rapae on Brassica nigra. Entomol. Exp. Appl. 115, 161-170. doi: 10.1111/j.15707458.2005.00241.x

Van Emden, H. F., Eastop, V. F., Hughes, R. D., and Way, M. J. (1969). The ecology of Myzus persicae. Annu. Rev. Entomol. 14, 197-270. doi: 10.1146/annurev.en. 14.010169.001213

van Geem, M., Gols, R., Raaijmakers, C. E., and Harvey, J. A. (2016). Effects of population-related variation in plant primary and secondary metabolites on aboveground and belowground multitrophic interactions. Chemoecology 26, 219-233. doi: 10.1007/s00049-016-0222-0

Vandegehuchte, M. L., De Le Peña, E., and Bonte, D. (2010). Interactions between root and shoot herbivores of Ammophila arenaria in the laboratory does not translate into correlated abundances in the field. Oikos 119, 1011-1019. doi: 10.1111/j.1600-0706.2009.18360.x

Wang, B., Liu, J., Tian, Z., Song, B., and Xie, C. (2005). Monitoring the expression patterns of potato genes associated with quantitative resistance to late blight during Phytophthora infestans infection using cDNA microarrays. Plant Sci. 169, 1155-1167. doi: 10.1016/j.plantsci.2005.07.020

Wardle, D. A., Bardgett, R. D., Klironomos, J. N., Setälä, H., van der Putten, W. H., and Wall, D. H. (2004). Ecological linkages between aboveground and belowground biota. Science 304, 1629-1633. doi: 10.1126/science.1094875

Wubben, M. J. E., Jin, J., and Baum, T. J. (2008). Cyst nematode parasitism of Arabidopsis thaliana is inhibited by salicylic acid (SA) and elicits uncoupled SAindependent pathogenesis-related gene expression in roots. Mol. Plant Microbe Interact. 21, 424-432. doi: 10.1094/MPMI-21-4-0424

Wurst, S., and van der Putten, W. H. (2007). Root herbivore identity matters in plant-mediated interactions between root and shoot herbivores. Basic Appl. Biol. 8, 491-499. doi: 10.1016/j.baae.2006.09.015

Zhu-Salzman, K., Salzman, R. A., Ahn, J. E., and Koiwa, H. (2004). Transcriptional regulation of sorghum defence determinants against a phloem-feeding aphid. Plant Physiol. 134, 420-431. doi: 10.1104/pp.103.028324

Conflict of Interest Statement: The authors declare that the research was conducted in the absence of any commercial or financial relationships that could be construed as a potential conflict of interest.

Copyright (c) 2017 Hoysted, Lilley, Field, Dickinson, Hartley and Urwin. This is an open-access article distributed under the terms of the Creative Commons Attribution License (CC BY). The use, distribution or reproduction in other forums is permitted, provided the original author(s) or licensor are credited and that the original publication in this journal is cited, in accordance with accepted academic practice. No use, distribution or reproduction is permitted which does not comply with these terms. 